\title{
The Coaches' Ability to Solve Their Administrative Problems They Face in Some Soccer Academics in Jordan
}

\author{
Hasan Mohammed Al-Khaldi \\ Department of Coaching and Sport Management, The Hashemite University, Zarqa, Jordan
}

Received October 30, 2020; Revised December 3, 2020; Accepted December 30, 2020

\section{Cite This Paper in the following Citation Styles}

(a): [1] Hasan Mohammed Al-Khaldi , "The Coaches' Ability to Solve Their Administrative Problems They Face in Some Soccer Academics in Jordan," International Journal of Human Movement and Sports Sciences, Vol. 8, No. 6, pp. 494 497, 2020. DOI: 10.13189/saj.2020.080623.

(b): Hasan Mohammed Al-Khaldi (2020). The Coaches' Ability to Solve Their Administrative Problems They Face in Some Soccer Academics in Jordan. International Journal of Human Movement and Sports Sciences, 8(6), 494 - 497. DOI: 10.13189/saj.2020.080623.

Copyright $\bigcirc 2020$ by authors, all rights reserved. Authors agree that this article remains permanently open access under the terms of the Creative Commons Attribution License 4.0 International License

\begin{abstract}
This study aimed to identify the coaches' ability to solve the administrative problems they face in some soccer academies in Jordan. The study sample consisted of (60) parents that were chosen randomly. The researcher prepared a questionnaire composed of two axes; the first one is related to the problems that players face in the academies, which simultaneously weaken their technical development, the second one is all about the Coaches' actions in disciplining the players' negative behaviors. After conducting the appropriate statistical treatments, the study found crucial results which are the following: firstly, there are many problems that the players face in the soccer academies that weaken their technical development at the same time. Secondly, the coach is not able enough to solve the problems that the players face. The recommendations are as the following: assigning administrative staff with technical staff to work separately but having the same goals is something necessary. The administrative and the technical staff should attend training courses to develop their skills in solving the administrative problems that they face in the work environment (Soccer Academy).
\end{abstract}

Keywords Coaches, Ability to Solve, Administrative Problems, Soccer, Academics

\section{Introduction}

Diversity of the environments that care about talented people in society is based on the educational system to develop the talented people. In the 21st Century, fast-paced change in management is the norm. Conceptualizing sport management as a specialized practice area or skill implement change is not what is needed, but rather building a capacity for change into sport human resources (coaches, administrators). Every sport job and every sport training unit or sport academic are subject to change. Therefore, everyone (coaches, administrators) needs solving problems skills to deal with players. [1-2]

The management developed greatly; it became a tool used in professional development adapted with changes according to developments regarding many different concepts of management [3]. Sport management means the control of the organization, its components and the factors of its functioning, and managers are experts for mastering organizations. Furthermore, sport management is important to transfer and influence organization like sport clubs, associations, and sport academics. So, change is necessary to improve the abilities of workers and administrative leaders who plan to formulate a policy in which deals with the talented people having said that management is ruined if there is no creativity [4].

The aware management helps provide and let the individual acquire the methods, experiences, and the 
necessary scientific trends for any work environment. This is to help provide the best performance possible and to prepare him/her to do the future functional tasks according to thoughtful scientific scheme [5].

The management plays a significant role in developing the staff in addition to knowing the properties that the unofficial groups have while taking into consideration that the work environment is regarded as a human society. Management depends on providing an appropriate work atmosphere that encourages individuals to work cooperatively and aims to achieve the work goals and satisfy the individual's needs and desires through coordinating their efforts. [6].

There are many justifications to develop the administrative work including decreasing profits, the inability to discuss, the large number of employees who are absent, and increasing complaints...etc. ([7-8]. Hence, Management is essential to professional practice in sport organization. Sport managers are people who take the correct actions in the right way. Sports administrators are responsible for empowering subordinates to establish and

achieve goals for sport organizations and sport academics.

This study is important since several sport academies depend on coaches when they try to solve their problems, they cannot assign specialist administrators since it contradicts the concept of profits. This study tries to diagnose the problems that the soccer academies face and find out the suitable solutions.

\subsection{The Problem of the Study}

As a technical and administrative consultant for some soccer academies in Jordan, the researcher observed that most of the academies do not assign a soccer administrative specialist who is able to solve the problems that the academy faces. The administrative problems need an expert in the administrative field to solve the problems in an administrative, educational and scientific way. The researcher observed that the absence of a temporary solution for these ongoing problems leads to not solving the problems in the future and it will affect the academy negatively, morally, and materialistically.

\subsection{The Study Objectives:}

This study aimed to:

- Identify the administrative problems, which the plays face in soccer academies,

- Identify the coach's administrative behavior to control players' negative behavior

\section{Materials and Methods}

The researcher used the descriptive method since it fits this kind of study. The study sample consists of (60) parents of players that were chosen randomly. The researcher prepared a questionnaire that has two axes; the first one: the administrative problems that are done by the players in the academies which leads to weaken their development in performance, the second one is related to the coach's behavior to make the players' negative conducts disciplined.

Additionally, the researcher depended on the content's validity. The questionnaire is viewed by (8) sports management experts to identify how clear the statements and suit the axis that was used are. The entire study sample agreed on the clarity of the statements and the axes which come within. The researcher used the Cronbach's alpha equation; coefficient of stability is $(0.87)$ which is suitable statistically. Statistical coefficients:

The researcher used the statistical SPSS and used what is suitable for this kind of study.

\section{Results and Discussion}

The first question is as the following: "what are the administrative problems that the players do which lead to weaken their performance in some academies?"

Percentages and Table(1) have been used to display the results.

Table (1) shows that most of the study sample agreed on the statements of the questionnaire. The coach cannot control all the players in the soccer academies for numerous reasons. For example, he is responsible for not only the technical task but also the administrative obligations, and because of the big number of the players he is not qualified enough educationally and administratively to solve all the administrative problems the players face, or the stadiums are not suitable and safe to play on which leads to conflicts and struggles between the players and this is due to the absence of the written instructions which prevent these kinds of conflicts.

A study conducted by [9], which emphasizes on the necessity of forming an integrated team. Integrated working provides the tools to identify coaches' administrative problems. Sport facilities limitation and lack of clear career structure, and limited opportunities for promotion, Moreover, no highlighting on the team work vision cause administrative problems.

The administrative work is separated from the technical work but it integrates with outputs through providing a safe work environment and harmonious work team and adopting new methods to solve the administrative problems the individuals face.

The second question is as the following: "what is the coach's behavior to make the players' negative conducts disciplined?"

To answer this question, the percentages have been used as shown in table (2). 
Table 1. The percentage of the study sample's response on the administrative problems were done by the players in the academies $(\mathrm{N}=60)$

\begin{tabular}{|c|c|c|c|c|}
\hline No. & Statement & agreed & neutral & Not agreed \\
\hline 1 & The players are late on time & $45 \%$ & $15 \%$ & $40 \%$ \\
\hline 2 & Most of the players come to the academy for leisure & $57 \%$ & $27 \%$ & $16 \%$ \\
\hline 3 & Most of the players work on creating conflicts and struggles & $17 \%$ & $22 \%$ & $61 \%$ \\
\hline 4 & The large number of players is a big problem & $72 \%$ & $5 \%$ & $23 \%$ \\
\hline 5 & The coach ignores matches versus other academies & $79 \%$ & $3 \%$ & $18 \%$ \\
\hline 6 & The coach cares about some players and others not & $81 \%$ & $7 \%$ & $12 \%$ \\
\hline 7 & The players don't get the tools and sport clothes on time & $78 \%$ & $13 \%$ & $9 \%$ \\
\hline 8 & The stadiums used are not suitable enough to play on & $69 \%$ & $15 \%$ & $16 \%$ \\
\hline 9 & The coach needs a long period of time to follow up the players since he is the & $83 \%$ & $7 \%$ & $10 \%$ \\
\hline 10 & only one who is taking the entire responsibility & $71 \%$ & $6 \%$ & $13 \%$ \\
\hline 11 & The coach's following up a large number of players weakens the players' & $87 \%$ & $10 \%$ & $3 \%$ \\
\hline 12 & The coach solves the problems arise between the players traditionally & $80 \%$ & $12 \%$ & $8 \%$ \\
\hline
\end{tabular}

Table 2. The coach's behavior to make the players' negative conducts disciplined with ( $\mathrm{N}=60)$

\begin{tabular}{|c|c|c|c|c|}
\hline No. & Statement & agreed & neutral & Not agreed \\
\hline 1 & $\begin{array}{c}\text { The coach makes an internal list contains procedures to } \\
\text { make the players' negative conducts disciplined }\end{array}$ & $28 \%$ & $55 \%$ \\
\hline 2 & $\begin{array}{c}\text { The coach encourages the players who are committed } \\
\text { behaviorally }\end{array}$ & $47 \%$ & $6 \%$ & $47 \%$ \\
\hline 3 & $\begin{array}{c}\text { The coach solves the problems fairly between the } \\
\text { players }\end{array}$ & $27 \%$ & $5 \%$ & $38 \%$ \\
\hline 4 & $\begin{array}{c}\text { The coach has to form a protocol that all the players } \\
\text { should follow }\end{array}$ & $57 \%$ & $4 \%$ & $13 \%$ \\
\hline 5 & The coach has to attend the training courses early & $83 \%$ & $53 \%$ \\
\hline 6 & $\begin{array}{c}\text { The coach should prepare the work environment before } \\
\text { the players come }\end{array}$ & $37 \%$ & $7 \%$ & $42 \%$ \\
\hline 7 & $\begin{array}{c}\text { The coach communicates with parents to look for the } \\
\text { players' interest }\end{array}$ & $51 \%$ & $4 \%$ & $17 \%$ \\
\hline 8 & $\begin{array}{c}\text { The coach chooses the distinguished players and lets the } \\
\text { community know about them }\end{array}$ & $79 \%$ & $8 \%$ & $25 \%$ \\
\hline 9 & The coach should flatter the parents & $67 \%$ & $9 \%$ & $45 \%$ \\
\hline 10 & The coach holds friendly matches with other teams with \\
\hline 11 & The planned program & $37 \%$ & $31 \%$ & $54 \%$ \\
\hline 12 & The coach follows up the players academically & $41 \%$ & $51 \%$ \\
\hline
\end{tabular}

Table (2) shows that most of the sample agreed on the statement that the coach is weak in the administrative tasks, either in forming internal lists or administrative staffs as shown in the protocol that he does not put in which the administrative work should followed by the players. Moreover, the coach does not organize a previous plan to hold sport competitions or recreational trips for the players and he compliments the parents usually excepting something out of them.

The coach doesn't formulate a program or agenda containing the work priorities appropriately since he is the only one who is taking the entire responsibility of developing the players and he is working under big pressure and as a result, this causes him to think to end his work and not doing other things which benefit his soccer academy which has a big number of players who should be controlled administratively. Furthermore, sometimes the coach does not focus on his mistakes in work and if he works very well that is because of his personal interests which lead him to compliment some parents excepting something in return and this will affect the work negatively in present and future. On other hand there is a need for a Sports Administrator who will assist the coach in many things such as answer phone calls and respond to emails, manage academic budgets, order sporting and office equipment as needed and schedule practice time. Reference [10] emphasizes on the idea that requires a manger who has several traits that make him qualified to deal with the talented people besides their culture taking into consideration the difference between success and 
failure which is in the method chosen to deal with others. The distinguished manager is the person who has the ability to communicate with players, have the whole responsibility and manage the conflicts arise between the players besides the skills that make him analyze data and form appropriate plans [11].

\section{Conclusion}

Sports administrators help to ensure the smooth running of a sports organization and sport academics, which may range from reception work at academic sports to marketing. Sports administrators have a range of responsibilities to facilitate work. There are many administrative problems that the coach faces in the soccer academies in Jordan which weaken the level of the players' development since the coach is the only one who is working with the players. The study shows that the coach is not able enough to solve the administrative problems that he faces in work especially with players in a scientific, administrative, and educational way. Study cited by [12] found that the behavior of coaches is critical towards optimal development and performance of athletes.

The study recommends the necessity of treating the administrative problems that the players face in the soccer academies and the necessity of forming an administrative staff besides the technical staff help provide appropriate work environment. Moreover, the study recommends holding intensive training courses to the technical and administrative staffs to develop their administrative skills in facing the administrative problems in work [13]. Furthermore, if sport organization and sport academic ensure they hire professional sport administrator, they can success to reach high goals. Administrator is responsible for investigating and resolving the issue in an efficient and timely manner.

\section{REFERENCES}

[1] D. Minbaeva, and D. G. Collings. Seven myths of global talent management. The International Journal of Human Resource Management 24(9): 1762-1776. 2013. https://doi.org/10.1080/09585192.2013.777539
[2] S. Swailes, Y. Downs, and K. Orr. Conceptualising inclusive talent management: Potential, possibilities and practicalities. Human Resource Development International 17(5): 529 544.2014. doi:10.1080 /13678868.2014.954188.

[3] J. Purcell. Disengaging from engagement. Human Resource Management Journal, 24, 241- 254. 2014 doi:10.1111/1748 $-8583.12046$.

[4] G. Ahmetoglu, X. Harding, R. Akhtar, and T. Chamorro-Premuzic.. Predictors of creative achievement: Assessing the impact of entrepreneurial potential, perfectionism, and employee engagement. Creativity Research Journal, 27, 198-205. 2015. doi:10.1080/1040041 9.2015.1030293.

[5] K. C. Lee, S. Lee, I. Kang. KMPI: Measuring knowledge management performance. Information and Management, 42(3), pp. 469-482. 2005. https://doi.org/10.1016/j.im.2004 .02 .003

[6] S. M. Kompaso, and M. S. Sridevi. Employee engagement: The key to improving performance. International Journal of Business and Management,5, 89-98. 2010. doi:10.5539/ijb m.v5n12p89.

[7] M.G. Patterson, M.A. West, R. Lawthom, and S. Nickell. Impact of people Management Practices on business Performance "Institute of Personal and Development, pp 5-13.London. 1997.

[8] Y.Cohen-Charash, and P. E. Spector. The role of justice in organizations: A metaanalysis. Organizational Behavior and Human Decision Processes, 86(2), 278- 321. 2001. https://doi.org/10.1006/obhd.2001.2958

[9] P. Capplli. Talent Management for the Twenty First Century, Harvard Business Reviews. pp 74-81.2008.

[10] L. Berger and Dorothy. B. The Talent Management Hand Book - Creating Organizational Excellence Lanceabenger and Associates. pp 183-199 2004.

[11] V. E. McCuiston, and A. DeLucenay. Organization development quality improvement process: Progress energy's continuous business excellence initiative. Journal of Business Case Studies, 6, 7-18. 2010.doi:10.19030/jbcs. v6i6.255.

[12] E. H.John., W.A Edward., P. Dietmar ., S. Thomas , "Elite Student-Athletes' Perceptions of Coaches' Behavior during the 23rd World Universiade Games in Kazan, Russia," International Journal of Human Movement and Sports Sciences, Vol. 5, No. 4, pp. 68 - 76, 2017. DOI: 10.13189/saj.2017.050402.

[13] L. Evans. Professionalism, professionality and the development of education professionals. British journal of educational studies56 (1),20-38 2008. https://doi.org/10.11 11/j.1467-8527.2007.00392.x 